\title{
Modelling the contribution of sea salt and dimethyl sulfide derived aerosol to marine $\mathrm{CCN}$
}

\author{
Y. J. Yoon ${ }^{1,2}$ and P. Brimblecombe ${ }^{1}$ \\ ${ }^{1}$ School of Environmental Sciences, University of East Anglia, Norwich NR4 7TJ, UK \\ ${ }^{2}$ Now at: Department of Experimental Physics, National University of Ireland Galway, Galway, Ireland
}

Received: 27 July 2001 - Published in Atmos. Chem. Phys. Discuss.: 3 September 2001

Revised: 26 November 2001 - Accepted: 13 December 2001 - Published: 14 January 2002

\begin{abstract}
The concentration of cloud condensation nuclei $(\mathrm{CCN})$ in the marine boundary layer (MBL) was estimated from dimethyl sulfide (DMS) flux, sea salt (SS) emission, and aerosols entrained from the free troposphere (FT). Only under clean air conditions, did the nucleation of DMS derived sulfur (DMS CCN) contribute significantly to the MBL $\mathrm{CCN}$. The accommodation coefficient for sulfuric acid mass transfer was found to be a very important parameter in the modeling the contribution of DMS to MBL CCN. The relationship between seawater DMS and MBL CCN was found to be non-linear mainly due to the transfer processes of sulfuric acid onto aerosols. In addition, sea salt derived CCN (SS $\mathrm{CCN}$ ) and entrained aerosol from the FT (FT CCN) affected the MBL CCN directly, by supplying CCN, and indirectly, by behaving as an efficient sink for sulfuric acid. The SS $\mathrm{CCN}$ explained more than $50 \%$ of the total predicted MBL $\mathrm{CCN}$ when wind speeds were moderate and high. Sea salt and FT aerosol may often be more efficient sources of MBL CCN than DMS.
\end{abstract}

\section{Introduction}

Aerosols in marine air influence planetary albedo both indirectly, by forming cloud condensation nuclei CCN and increasing cloud-top reflectivity, and directly, by backscattering incoming solar radiation. Because the global radiation budget is sensitive to the amount of cloud and their reflectivity towards solar radiation, the CCN, on which cloud droplets can form, play an important role in the Earth's climate. Charlson et al. (1987) suggested the existence of a feedback mechanism between climate change and the flux of oceanic DMS. This proposed climate feedback mechanism is commonly known as the CLAW hypothesis after the

Correspondence to: Y. J. Yoon (y.yoon@ nuigalway.ie) four founding authors. Dimethyl sulfide produced by marine phytoplankton is ventilated into the MBL, and oxidized to form sulfur compounds and ultimately sulfate aerosols. These aerosols form $\mathrm{CCN}$ in the remote marine atmosphere. These $\mathrm{CCN}$ affect the cloud albedo and global radiation budget. The change in cloud albedo results in global temperature perturbation which affects the productivity of marine eco-systems and hence the concentration of oceanic DMS.

In this hypothesis, authors assumed that the oxidation of DMS as the major source of CCN over the oceans. Charlson et al. (1987) set up their argument on the strong belief that the non-sea salt (NSS) sulfate aerosols, which are final products of atmospheric DMS oxidation, are the major source of CCN in the remote marine air. They argued that sea salt cannot act as $\mathrm{CCN}$ because the concentration of sea salt particles at cloud level is typically not more than $1 \mathrm{~cm}^{-3}$ (Hobbs, 1971). This assumption in the CLAW hypothesis that sea salt cannot act ac $\mathrm{CCN}$ in the marine air has been challenged since its initial statement (Blanchard and Cipriano, 1987; O’Dowd and Smith, 1993). Moreover, the nucleation ability of DMS derived sulfuric acid in the MBL is still under debate (Katoshevski et al., 1999; Pirjola et al., 2000).

The role of sea salt as a major CCN source has been supported by numerous laboratory and field studies in the last decade (Blanchard and Cipriano, 1987; Cipriano et al., 1987; O'Dowd and Smith, 1993; Murphy et al., 1998; O’Dowd et al., 1999a, O'Dowd et al. 1999b). Blanchard and Cipriano (1987) argued that the background concentration of sea salt particle is $15-20 \mathrm{~cm}^{-3}$, which can serve as CCN. They suggested this value based on field measurements and argued that the biological regulation of the climate is less obvious than CLAW hypothesis. More recently, using a volatility technique, O'Dowd and Smith (1993) and O'Dowd et al. (1999a) succeeded in distinguishing non-sea salt accumulation mode aerosol from sea salt $\mathrm{CCN}$ and quantified the accumulation mode sea salt aerosol concentrations as a func- 


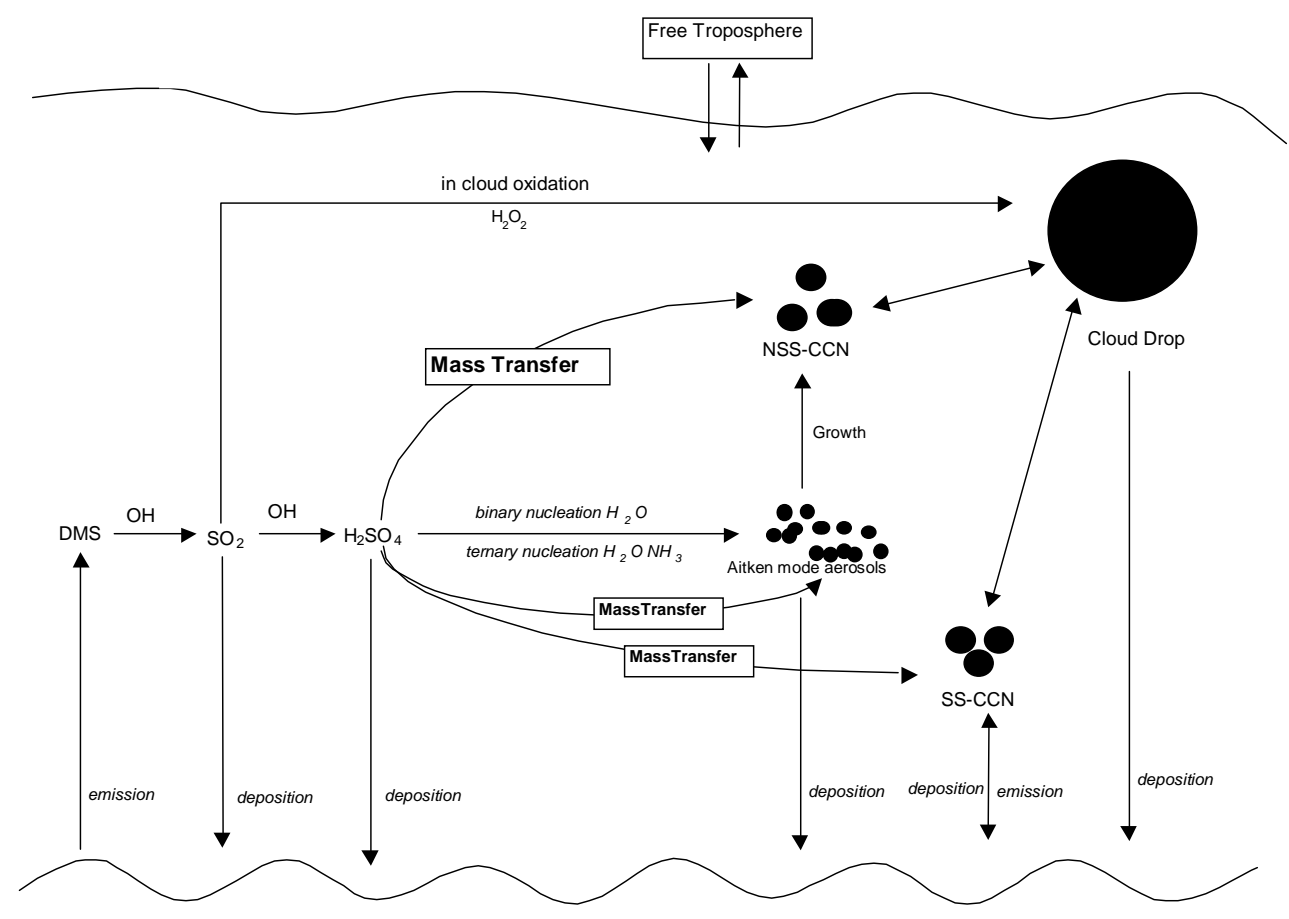

Fig. 1. The structure of the marine boundary layer CCN formation from DMS and sea salt flux for this work (the original figure was adapted from Raes, 1995).

tion of wind speeds up to $17 \mathrm{~m} \mathrm{~s}^{-1}$. They concluded that sea salt can act as major CCN source. They also argued that sea salt aerosols are well mixed throughout the MBL because these aerosols have similar radii to sulfate aerosols. As a result it is likely that sea salt aerosols formed via film and jet drops may act as important sources of CCN in the MBL and they could dominate the concentration of total $\mathrm{CCN}$ under moderate and high wind speeds. Murphy et al. (1998) also supported these arguments. They measured chemical composition of accumulation mode marine aerosols and found that almost all particles larger than $0.13 \mu \mathrm{m}$ contained sea salt under unpolluted conditions.

Katoshevski et al. (1999) and Pirjola et al. (2000) have challenged the dependency of marine $\mathrm{CCN}$ concentration on DMS flux. Katoshevski et al. (1999) argued that aerosol concentration in MBL is very sensitive to the entrainment fo free troposheric aerosols and sea salt emission. They proposed that a prediction of the relative contribution to MBL CCN by sea salt and DMS derived sulfate is important to elucidate the relationship between marine biota and climate. Pirjola et al. (2000) also elucidated that DMS flux in MBL alone cannot explain new particle formation, instead they suggested that additional condensable species other than DMS-derived sulfuric acid is required to help thermodynamically stable sulfate clusters grow into detectable particle size.

As highlighted, the MBL CCN act as one of the key parameters in the Earth radiation balance. It is likelihood that $\mathrm{SS}$ is an efficient $\mathrm{CCN}$ source in the MBL, means that its role within the CLAW should be investigated. It is also important to investigate an effect which could arise from the interaction between DMS derived sulfur compounds and aerosols in the MBL. The main goals of this study are to model the MBL CCN concentration from various sources, such as DMS emission from seawater, SS flux, and entrainment of aerosols from the free troposphere.

\section{MBL CCN model - description and considerations}

In this research, MBL CCN were assumed to originate from marine DMS and SS. In addition, the entrainment of FT aerosols into the MBL was also considered as a source of $\mathrm{CCN}$ in the MBL. Some direct sources to the MBL, such as volcanic emissions, shipping emissions and transport from continents, are not explicitly treated. This simplified approach may underestimate the $\mathrm{CCN}$ concentration in the MBL because anthropogenic contributions to the MBL aerosol were ignored at the present stage. Nevertheless this simplification is a reasonable method in assessing the contribution of natural sources to the MBL aerosol system.

The structure of the MBL aerosol model for this work is outlined in Fig. 1. The accumulation mode aerosols which can act as $\mathrm{CCN}$ are categorised into two types according to their origins, SS CCN and NSS CCN. The direct emission of SS CCN into the marine atmosphere was modelled following O'Dowd et al. (1997). The model for NSS CCN formation from DMS was adopted and modified from Pandis 
et al. (1994) and Russell et al. (1994) (hereafter these two models will be cited as the P\&R model). In addition to these two processes, the mass transfer of sulfuric acids onto existing aerosols were modelled by adopting the $\mathrm{H}_{2} \mathrm{SO}_{4}$ mass accommodation coefficient from Jefferson et al. (1997). The entrainment of free tropospheric gases and aerosols into the MBL are also considered as sources of MBL CCN.

\subsection{Sea salt and CCN}

A relationship between the film drop concentration and wind speed by O'Dowd et al. (1977) was used to estimate the SS $\mathrm{CCN}$ concentration in this work. These concentrations were described using a logarithmic relationship between wind speed and film drop SS:

$\log N_{\mathrm{SS}-\mathrm{CCN}}=0.095 U_{10}+0.283$,

where $N_{\mathrm{SS}-\mathrm{CCN}}$ is the $\mathrm{SS} \mathrm{CCN}$ number concentration $\left(\mathrm{cm}^{-3}\right)$ and $U_{10}$ the wind speed at $10 \mathrm{~m}$ above the sea surface $\left(\mathrm{m} \mathrm{s}^{-1}\right)$.

In this research, the contribution of SS to the MBL aerosol over a long time period needed to be considered because this work has assumed a steady state MBL CCN concentration. The parameter suggested by O'Dowd et al. (1997) as shown in relationship (1) was based on the average wind speed for one hour (O'Dowd, personal communication, 2000). In order to estimate a steady state SS CCN concentration from climatological wind data, such as global monthly mean wind speed distribution, the fluctuation of wind speed should be taken into account. This fluctuation of wind speed was approximated in this work using the Weibull distribution of wind speed probability.

The climatological SS CCN concentration $\left(\bar{N}_{\mathrm{SS}-\mathrm{CCN}}\right)$ was estimated using the relationship:

$\bar{N}_{\text {SS-CCN }}=\int N_{(U 10)} f_{(U 10)} d U$

Here, $N_{(U 10)}$ is directly estimated from mean wind speed using Eq. (1) and $f_{(U 10)}$ represents the wind speed as the Weibull probability density function:

$f\left(U_{10}\right)=\alpha \beta U_{10}{ }^{\beta-1} \exp \left(-\alpha U_{10}{ }^{\beta}\right)$.

This Weibull distribution is frequently used to describe the wind speed distribution over the ocean (Wanninkhof, 1992; Erickson and Taylor, 1989). In this study, the shape parameter $(\beta)$ was assumed to be 2.0 (Palutikof, personal communication, 2000) and $\alpha$ was calculated using Eq. (4):

$\alpha=\left(\frac{\Gamma\left(1+\beta^{-1}\right)}{U_{10}}\right)^{\beta}$,

where $U_{10}$ stands for the mean wind speed and $\Gamma$ the Gamma function.

Figure 2 shows the SS CCN concentration derived from Eq. (1) after considering the Weibull probability density

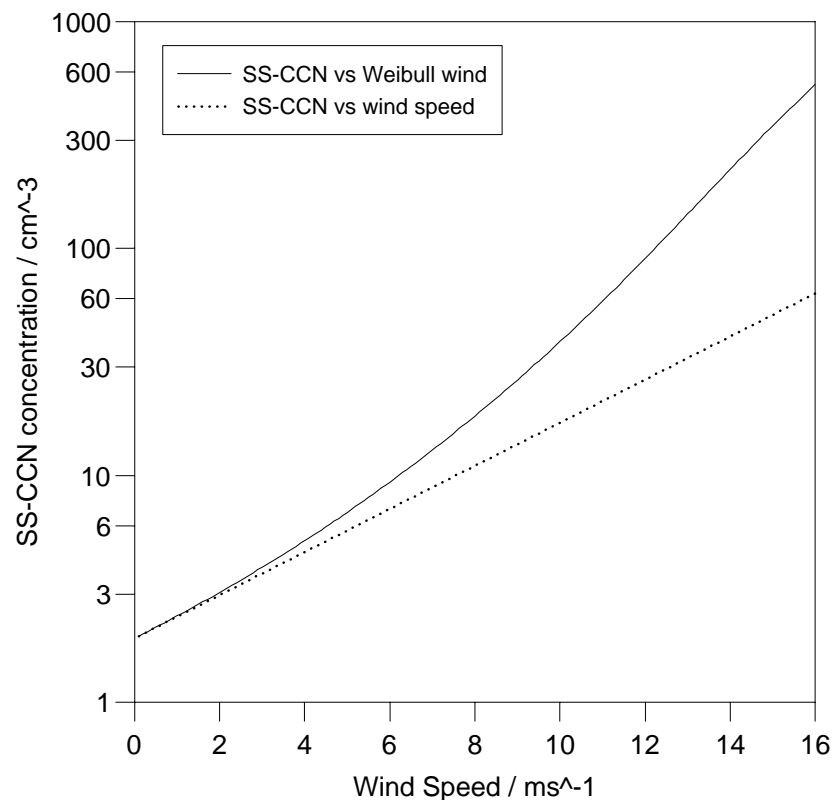

Fig. 2. Directly estimated SS CCN concentration from wind speed from O'Dowd et al. (1997)'s relation (dotted line) and climatological SS CCN estimated considering the Weibull wind distribution (solid line). Note that the wind speed means are averaged for a period longer than 1 month and extremely high mean speeds are very rare.

function (Eq. 2). Though the probability of extremely high wind speed is very low, the SS CCN concentration at this speed is very high because of the logarithmic relationship. This makes the re-estimated SS CCN, shown as a solid line in Fig. 2, steeply increase at high mean wind speeds. This high value, up to $500 \mathrm{~cm}^{-3}$, may be misleading because the relationship shown in Eq. (1) has only been tested for wind speeds lower than $17 \mathrm{~m} \mathrm{~s}^{-1}$. For the default case simulation, a mean wind speed of $8 \mathrm{~m} \mathrm{~s}^{-1}$ was used. The climatological SS CCN concentration, which considered the fluctuation of wind speeds over the ocean, was calculated as $18 \mathrm{~cm}^{-3}$. This was higher than the SS CCN concentration $\left(11 \mathrm{~cm}^{-3}\right)$ derived from Eq. (1) considering a constant average wind speed.

\subsection{MBL-FT exchange}

The P\&R model only dealt with the MBL as a closed system. An exchange between the MBL and the FT is believed to be possible even during inversions, through turbulent diffusion and microscopic phenomena (Kritz, 1983). The entrainment of aerosols from the FT into the MBL may provide a source of aerosols in the MBL (Raes, 1995; Clarke et al., 1998b; Raes et al., 2000). Clarke (1992) and Clarke et al. (1998b, 1999) reported, based on the experiments on the upper- tropospheric aerosol, new particles and sulfuric acid concentrations in the FT. Weber and McMurry (1996) also reported 
aerosol size distribution in the FT based on the observations at Mauna Loa Observatory. Their results suggest that the aerosol concentration in the FT shows a consistent shape. Clarke et al. (1998b) could find no evidence for particle production in the MBL in the first aerosol characterization experiment (ACE-1) experiment, but they reported enhanced 'new' particle formation in the FT. They suggested that the gases enter into the FT through cloud pumping, and then nucleation occurs. These particles subside into the MBL via entrainment process and contribute a quasi steady state particle and mass concentration in the MBL. Recently, Johnson et al. (2000) performed a Lagrangian experiment tracing a smart, constant balloon over the North Atlantic Ocean as part of the ACE-2 (The second aerosol characterization experiment) project. They concluded that sea salt aerosols, scavenging by cloud droplets, and the entrainment of FT air could affect the condensation nuclei concentration in the MBL. Furthermore, according to the report of Clarke et al. (1998a), the classic binary nucleation theory predicts no nucleation under the observed MBL conditions.

The exchange of gases and aerosol particles between the MBL and the FT was considered following Raes (1995):

$\frac{d C_{\mathrm{MBL}}}{d t}=S_{\mathrm{MBL}}-\frac{V e}{H}\left(C_{\mathrm{MBL}}-C_{\mathrm{FT}}\right)$,

where $C_{\mathrm{MBL}}$ and $C_{\mathrm{FT}}$ represent the concentration of a certain species $\mathrm{C}$ in the MBL and the FT, respectively, and $\mathrm{S}_{\mathrm{MBL}}$ means the sources and sinks in the MBL. The entrainment velocity $(\mathrm{Ve})$ is assumed to be $0.36 \mathrm{~cm} \mathrm{~s}^{-1}$ following Katoshevski et al. (1999) and Huebert et al. (1996) although this value is dependent on the spatially varying meteorological conditions. Recently, the entrainment rate between the MBL and the FT was reported as $0.7 \mathrm{~cm} \mathrm{~s}^{-1}$ for the eastern North Atlantic (Sollazzo et al., 2000). The MBL height $(H)$ was assumed to be $1000 \mathrm{~m}$ as a default. These entrainment of aerosols from the FT into the MBL was added to the P\&R model as Eq. (5). Katoshevski et al. (1999) adopted the FT aerosol concentration from Weber and McMurry, and this data was also used in our research. The approach in our study assumed that there are fluxes of DMS out of MBL and other DMS derived sulfur compounds have same concentration for both MBL and FT.

\subsection{DMS flux and CCN}

The DMS flux was estimated using Turner et al. (1996)'s method, which could then be used to estimate DMS concentration in the MBL. We modelled the gaseous reactions of DMS, $\mathrm{SO}_{2}$ and $\mathrm{H}_{2} \mathrm{SO}_{4}$ from the P\&R model. The two main features that have been modified are the FT entrainment (Eq. 5) and the mass transfer processes of sulfuric acids onto NSS and SS aerosols.

Concentrations for DMS and $\mathrm{SO}_{2}$ in the MBL were adapted from $\mathrm{P} \& \mathrm{R}$ including parameters which affect production and removal rates of these gases (see reactions (9) and (10) in Katoshevski et al., 1999). Concentration of gaseous sulfuric acid in the MBL was modified from $P \& R$ as:

$$
\begin{aligned}
& \frac{d\left(\mathrm{H}_{2} \mathrm{SO}_{4}\right)_{\mathrm{g}}}{d t}=k_{\mathrm{SO}_{2}(\mathrm{OH})_{\mathrm{g}}\left(\mathrm{SO}_{2}\right)_{\mathrm{g}}}-L_{\text {nucl }} \\
& \quad-K_{m t}^{1} N_{1}\left(\mathrm{H}_{2} \mathrm{SO}_{4}\right)_{\mathrm{g}}-K_{m t}^{2} N_{2}\left(\mathrm{H}_{2} \mathrm{SO}_{4}\right)_{\mathrm{g}} \\
& \quad-K_{m t}^{3} N_{3}\left(\mathrm{H}_{2} \mathrm{SO}_{4}\right)_{\mathrm{g}}-\left(K_{\left.\mathrm{dep}_{2} \mathrm{SO}_{4}\left(\mathrm{H}_{2} \mathrm{SO}_{4}\right)_{\mathrm{g}}\right) / H}\right. \\
& \quad-R_{\text {cloud }}^{\mathrm{H}_{2} \mathrm{SO}_{4}}+(\mathrm{Ve} / H)\left[\left(\mathrm{H}_{2} \mathrm{SO}_{4}\right)_{\mathrm{FT}}-\left(\mathrm{H}_{2} \mathrm{SO}_{4}\right)_{\mathrm{g}}\right]
\end{aligned}
$$

where $\left(\mathrm{H}_{2} \mathrm{SO}_{4}\right)_{\mathrm{g}}$ is $\mathrm{H}_{2} \mathrm{SO}_{4}$ concentration, $L_{\text {nucl }}$ the mass loss by nucleation and ignored at this stage, and $\mathrm{N}_{i}$ represents aerosol concentration for $i$ th species. Here, $i=1$ : Aitken mode aerosol, $i=2$ : NSS CCN, and $i=3$ : SS CCN. The sulfuric acid deposition velocity $\left(K_{\text {dep }}^{\mathrm{H}_{2} \mathrm{SO}_{4}}\right)$ was assumed as $1 \mathrm{~cm} \mathrm{~s}^{-1}$ (equivalent to $0.86 \mathrm{~d}^{-1}$ with $1000 \mathrm{~m}$ height). The term $R_{\text {cloud }}^{\mathrm{H}_{2} \mathrm{SO}_{4}}$ is $\mathrm{H}_{2} \mathrm{SO}_{4}$ mass transfer to cloud droplets and calculated using the relation, $\left\{f_{\text {cloud }} \times\left(\mathrm{H}_{2} \mathrm{SO}_{4}\right)_{\mathrm{g}}\right\}$.

The sectional mass transfer coefficient $\left(K_{m t}^{i}\right)$ for $i$ th species to the aerosol phase by condensation was calculated from Pandis et al. (1994)'s work as:

$K_{m t}^{i}=\frac{2 \pi D}{x_{i+1}-x_{i}} \int_{x_{i}}^{x_{i+1}} 10^{x} F(x) A(x) d x$,

where $x_{i}=\log _{10}\left(D_{i}\right), x_{i+1}=\log _{10}\left(D_{i+1}\right)$. Here $D_{i}$ and $D_{i+1}$ mean diameter of particle in micrometer, $D$ is diffusivity of sulfuric acids in air $\left(0.1 \mathrm{~cm}^{2} \mathrm{~s}^{-1}\right)$, and $F$ is a coefficient correcting for free molecular effects and can be calculated as:

$F(k n)=\frac{1+k n}{1+1.71 k n+1.33 k n^{2}}$.

In this relation, $k n$ represents the Knudsen number. In Eq. (7), $A$ is a coefficient correcting for interfacial mass transport and calculated using the equation:

$A=\left[1+1.33 k n F(k n)\left(\frac{1}{a_{e}}-1\right)\right]^{-1}$.

The term $a_{e}$ is an accommodation coefficient of sulfuric acid onto aerosols.

Figure 3 shows the mass transfer coefficient calculated using Eq. (7). The equation was integrated from 0.03 to 0.1 $\mu \mathrm{m}$ for Aitken mode aerosol $\left(N_{1}\right)$, and 0.1 to $0.6 \mu \mathrm{m}$ for accumulation aerosol $\left(N_{2}\right)$. It is clear from this figure that selection of accommodation coefficient plays an important role in modelling the amount of sulfuric acid transferred onto aerosols. Pandis et al. (1994) and Russell et al. (1994) used 0.02 as the accommodation coefficients from Van Dingenen and Raes (1991), and Fitzgerald and Hoppel (1998) used 0.1 as a default value for their MBL aerosol model. Recently, Jefferson et al. (1997) reported higher values compared with previous studies. They suggested an accommodation coefficient of $\mathrm{H}_{2} \mathrm{SO}_{4}$ onto $\left(\mathrm{NH}_{4}\right)_{2} \mathrm{SO}_{4}$ and $\mathrm{NaCl}$ as 0.73 and 0.79 , 


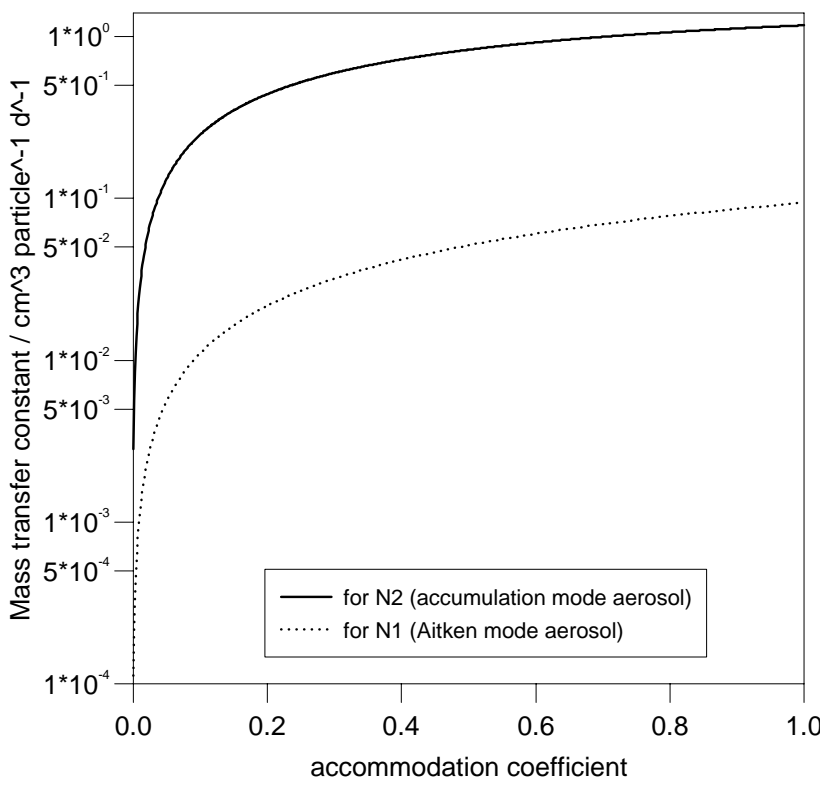

Fig. 3. Calculated mass transfer constant of sulfuric acids onto Aitken (dotted line) and accumulation mode (solid line) marine aerosols with various accommodation coefficients.

respectively. In this study, 0.70 was selected as a default value following Jefferson et al. (1997).

The aerosol size distribution spectrum was adopted from the P\&R's original study. They used bimodal distribution of marine aerosol and a series of step functions. Aerosols in the accumulation mode $(0.1 \mu \mathrm{m} 0.6 \mu \mathrm{m})$ were defined as $\mathrm{CCN}$ for this study. The Aitken and accumulation modemarine aerosol concentration from DMS oxidation and heterogeneous nucleation was modeled using the reactions in P\&R (see reactions (4) and (5) in Pandis et al., 1994).

\section{MBL CCN model - results and discussion}

\subsection{Default case simulation}

A modified P\&R model was used to simulate the concentration of MBL CCN derived from DMS flux, SS flux and FT entrainment. The initial marine air was assumed free of gaseous DMS, $\mathrm{SO}_{2}$, and $\mathrm{H}_{2} \mathrm{SO}_{4}$, and aerosols. Every reaction equation was integrated for 35 days to let these systems have enough time to reach their steady state. A test of this model showed that 35 days are enough time to stabilize. Default seawater DMS concentration was selected as $2 \mathrm{nmol}$ $1^{-1}$. The DMS flux from this assumption was calculated to be $4.7 \mu \mathrm{mol} \mathrm{m}^{-2} \mathrm{~d}^{-1}$ for this base case simulation. During the integration, a wind speed of $8 \mathrm{~m} \mathrm{~s}^{-1}$ was assumed as a mean value. Marine boundary air entered into the cloud once per a day, and a rain event occurred once every 10 days following the P\&R. Values from the 11th to 30th day were used to calculate the average concentration of each species.
The DMS concentration reached a stable diurnal cycle from the 4th day of integration. This reached a maximum value of $110 \mathrm{ppt}$ at 0700 and a minimum of $61 \mathrm{ppt}$ at 1600 . The average concentration for 20 days was 85 ppt. A (DMS)g concentration measurement by Andreae et al. (1995) reported a similar result over the tropical regions. The modelling result here also showed same (DMS)g diurnal variations reported by Yvon et al. (1996). The work by Yvon et al. (1996) reported higher DMS concentration than the result from this work because their sampling was done for the high seawater DMS concentrations ranging from 4 to $8 \mathrm{nmol}^{-1}$. The DMS diurnal cycle was mainly dominated by the concentration of $\mathrm{OH}$ radical. The $\mathrm{OH}$ concentration was assumed to show a maximum at noon and zero at night. During the night, DMS accumulated in the atmosphere because reactions with other species were ignored in this run for remote clean marine air. As the $\mathrm{OH}$ concentration increases until mid-day, their reactions with DMS become more active and the concentration of DMS decreases dramatically until 1600 . If the entrainment term was ignored, the mean DMS concentration was $115 \mathrm{ppt}$. This means that the net flux of DMS from the MBL to the FT reached up to $26 \%$ of the total oxidized amount. This process was not considered in the P\&R's approach although it now appears that this DMS loss by entrainment may suppress the formations of NSS CCN in the MBL.

The $\mathrm{SO}_{2}$ diurnal cycle showed an inverse phase relationship with DMS. This is because, in this simulation, DMS oxidation processes were assumed to be the only source of $\mathrm{SO}_{2}$. The mean concentration of $\mathrm{SO}_{2}$ was $45 \mathrm{ppt}$ and the diurnal variation ranged between 27 and 62 ppt. A measurement by Yvon and Saltzman (1996) also showed that the $\mathrm{SO}_{2}$ diurnal variation showed a negative correlation with the variation of (DMS)g concentration. In this default case simulation, the mean sulfuric acid concentration was $0.05 \mathrm{ppt}$. This gas phase $\mathrm{H}_{2} \mathrm{SO}_{4}$ concentration had 1-day and 10-day cycles. After the Sun rises, $\mathrm{OH}$ concentration increases and its reaction with $\mathrm{SO}_{2}$ starts and $\mathrm{H}_{2} \mathrm{SO}_{4}$ begins to form. The sulfuric acid concentration reached its maximum around noon. Along with this production route, gaseous $\mathrm{H}_{2} \mathrm{SO}_{4}$ was transferred to the surface of aerosols, or deposited to the sea surface. A measurement by Weber et al. (1998) also reported the typical sulfuric acid concentration in MBL as approximately $0.1 \mathrm{ppt}$. Though other measurements by Weber et. al. (1997) are available from continental sites, the sulfuric acid concentration showed similar diurnal variation to our result. Besides this 1-day cycle, the concentration of sulfuric acid showed a steep increase every 10 days. Rain events were assumed to occur every 10 days in this calculation. These rain events cleaned the MBL of gases and particles. As a result, the transfer of sulfuric acid onto aerosol particles was less effective which explains the sudden increase of sulfuric acid following a rain event.

The sulfuric acid concentration was sensitive to the accommodation coefficient because it determined the effectiveness of the transfer of sulfuric acid onto existing aerosols. 
(a)

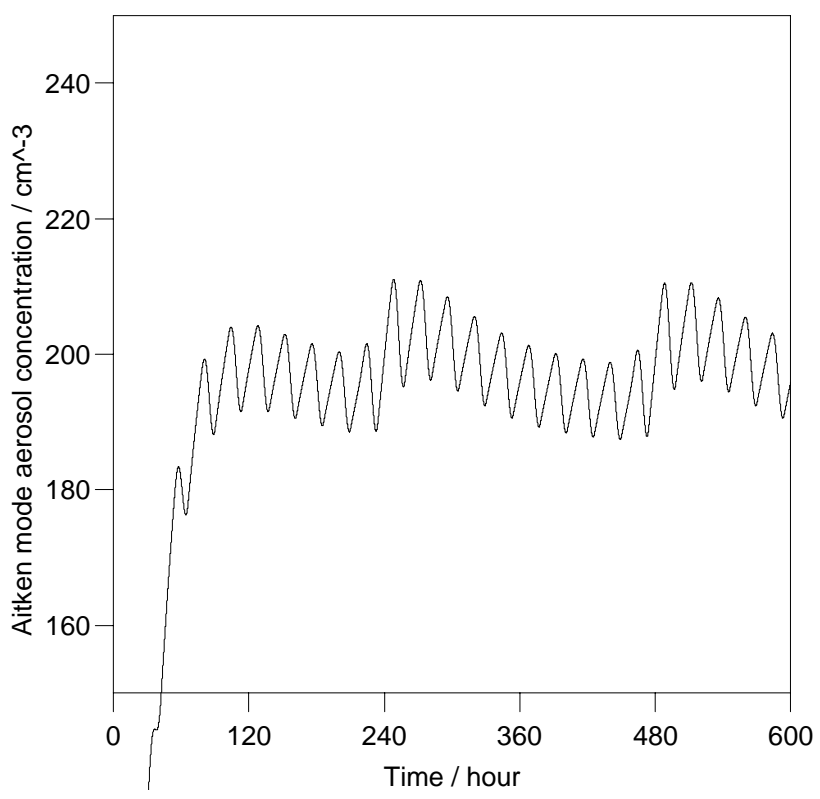

(b)

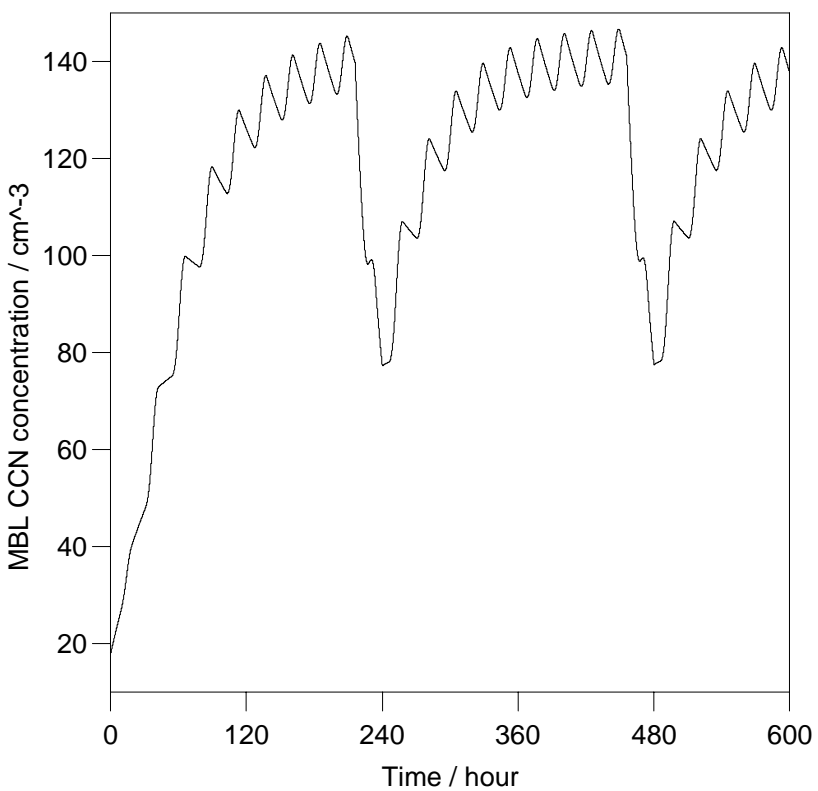

Fig. 4. Predicted variations in (a) Aitken and (b) accumulation mode aerosols. The entrainment terms were included in this case. The averaged concentration for $\mathrm{N}_{1}$ and $\mathrm{N}_{2}$ were 198 and $126 \mathrm{~cm}^{-3}$, respectively.

When this base case was re-simulated using an accommodation coefficient of 0.02 (a value used by the P\&R), the concentration of sulfuric acid rose to $0.34 \mathrm{ppt}$. This result was a factor of seven higher than the base case and affected the predicted concentration of MBL CCN. This will be discussed in the following section.

The estimated concentration variations for Aitken and accumulation mode MBL aerosol are shown in Fig. 4. There was a noticeable 10-day cycle for both modes because of the way the model simulates scavenging. As shown in Fig. 4a, Aitken mode aerosol occurred when MBL air was clean especially, after a rain event. As time proceeds, these Aitken mode aerosols grew to accumulation aerosols and their concentration decreased gradually until the next rain event. The 20 day averaged concentration of these small aerosols was $198 \mathrm{~cm}^{-3}$.

The variation of accumulation mode aerosol is shown in Fig. 4b. It reached a maximum value of $146 \mathrm{~cm}^{-3}$ before a rain event. During a rain event, this concentration dropped dramatically to $78 \mathrm{~cm}^{-3}$ but increased gradually when the event finished. The average concentration for these $\mathrm{CCN}$ was $126 \mathrm{~cm}^{-3}$.

These two size mode aerosols had an inverse phase diurnal cycle. In the case of Aitken mode aerosols (Fig. 4a), a maximum concentration was predicted at 0700 and a minimum at 1700 . By contrast, accumulation mode aerosols showed a maximum value at 1700 and minimum at 0700 (Fig. 4b), and this is because of the growth of Aitken mode aerosols into CCN.
With the mean wind speed as $8 \mathrm{~m} \mathrm{~s}^{-1}$, the SS CCN alone was estimated to be $18 \mathrm{~cm}^{-3}$. This accounted for $14 \%$ of the predicted total MBL CCN concentration. These wind derived SS CCN affected the MBL CCN simulation directly, by supplying $\mathrm{CCN}$, and indirectly, as a sink for sulfuric acid.

\subsection{Sensitivity tests}

\subsubsection{Sensitivity to the accommodation coefficient}

As highlighted in Sect. 2.3, one of the main features to be modified from the P\&R model was the accommodation coefficient $\left(a_{e}=0.70\right)$ for sulfuric acid transfer onto aerosols. The results of sensitivity test for this selection are shown in Fig. 5. With an accommodation coefficient of 0.02 , the mean $\mathrm{CCN}$ concentration was predicted to be $238 \mathrm{~cm}^{-3}$. This value was higher than the base case estimation by a factor of two. There was no change in the mean wind speed from the base case simulation, so the SS CCN concentration remained the same for these two simulations. Figure 3 showed that the mass transfer constant for accumulation mode aerosol was very sensitive to the choice of the accommodation coefficient. As a result, the lower accommodation coefficients made the transfer of sulfuric acid onto aerosol less efficient, and the nucleation process became more active. As shown in Fig. 5b, the concentration of $\mathrm{H}_{2} \mathrm{SO}_{4}$ was seven fold higher than the base case, and the mean concentration of sulfuric acid was calculated as $0.34 \mathrm{ppt}$ when the lower coefficient of 0.02 was used. This increase in sulfuric acid concentration accelerated the nucleation rate again, and as a result, the 
(a)

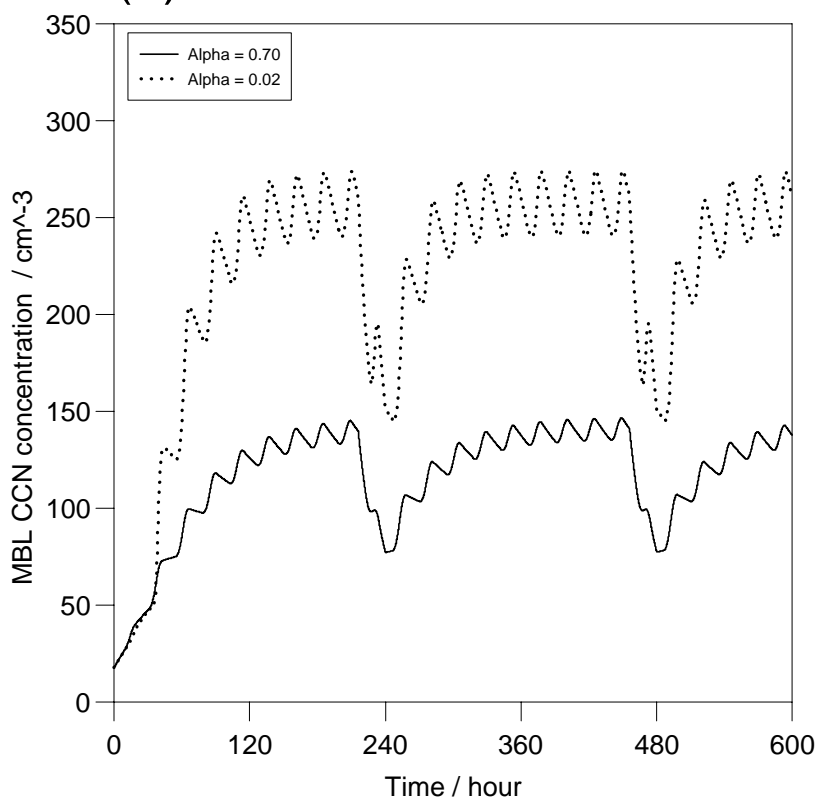

(b)

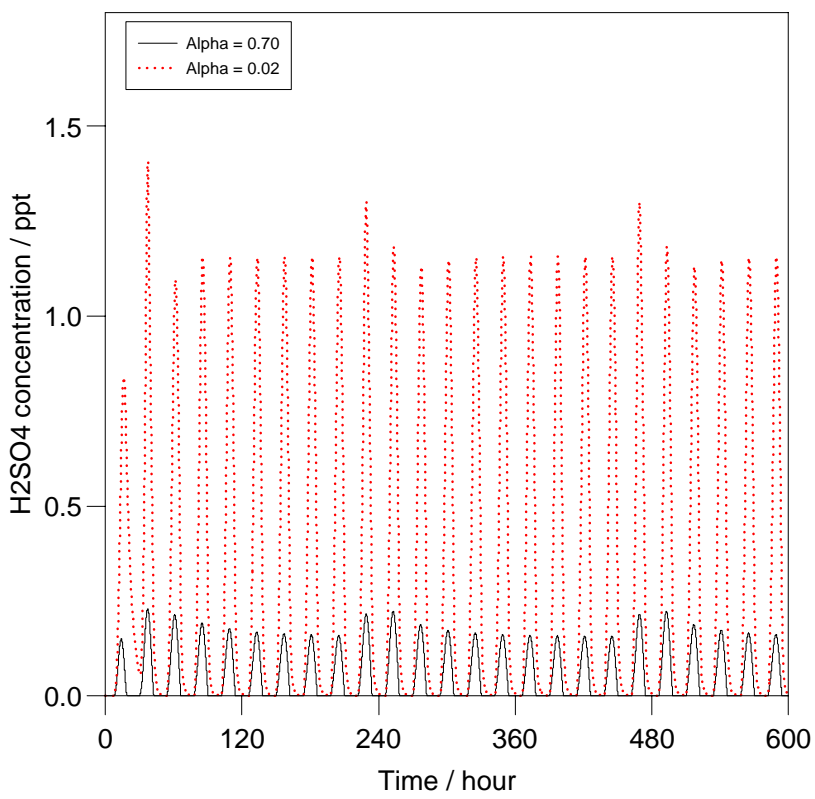

Fig. 5. (a) MBL CCN and (b) $\mathrm{H}_{2} \mathrm{SO}_{4}$ variation with $\alpha=0.02$ and $\alpha=0.70$. The entrainment terms in the reactions were included in this case. The averaged concentrations for MBL CCN and $\left(\mathrm{H}_{2} \mathrm{SO}_{4}\right) \mathrm{g}$ were $238 \mathrm{~cm}^{-3}$ and $0.34 \mathrm{ppt}$, when an accommodation coefficient of 0.02 was used instead of 0.70 .

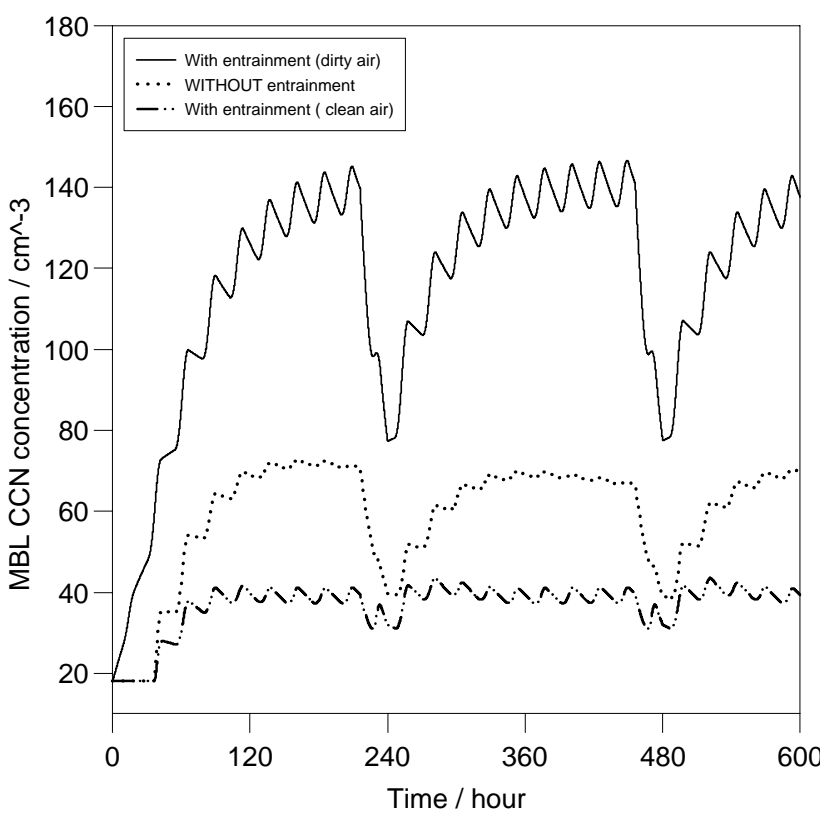

Fig. 6. $\mathrm{CCN}$ concentration with entrainment (solid line), without entrainment (dotted line), and with entrainment of clean air from FT (dashed line). The mean values for these simulation were 126, 63 and $39 \mathrm{~cm}^{-3}$, respectively.
MBL CCN concentration was much larger when using the P\&R's original concepts.

When the SS CCN contribution and FT entrainment were ignored, the DMS CCN concentration was predicted as $64 \mathrm{~cm}^{-3}$ with $a_{e}=0.70$, and $412 \mathrm{~cm}^{-3}$ with $a_{e}=0.02$, respectively. The only source of $\mathrm{CCN}$ in this simulation was assumed to be the nucleation of sulfuric acid, so the error caused by selecting a wrong accommodation coefficient became larger when other physical processes that supply CCN into the MBL were ignored.

\subsubsection{Sensitivity to the entrainment processes}

The role of entrainment of FT aerosols into the MBL was tested performing simulations with two assumptions; firstly there was no exchange between the MBL and the FT, secondly there was an exchange but the FT air was free of aerosols. The results of $\mathrm{CCN}$ variation for these experiments are shown in Fig. 6. For the three cases, including the default case, the diurnal variation patterns were similar, but the concentrations were lower for the two tests. When no entrainment was assumed, the mean $\mathrm{CCN}$ concentration was $63 \mathrm{~cm}^{-3}$. This value was half of the result from the default case simulation. This means that the aerosol entrainment from the FT may explain at least half of the $\mathrm{CCN}$ formation in MBL. A change in the entrainment velocity (Ve) did not affect the predicted MBL CCN concentration - 50\% increase or decrease in this velocity did not affect the calculated CCN seriously. The dashed line in Fig. 6 shows the 
Table 1. Change in the predicted 20-days average MBL CCN concentration for variations in each parameter used for the default case simulation

\begin{tabular}{|c|c|c|c|c|}
\hline Parameter & $\begin{array}{l}\text { Default } \\
\text { value }\end{array}$ & $\begin{array}{l}\text { Tested } \\
\text { value }\end{array}$ & $\begin{array}{l}\mathrm{CCN} / \\
\mathrm{cm}^{-3}\end{array}$ & $\begin{array}{r}\text { Change in } \\
\mathrm{CCN} / \%\end{array}$ \\
\hline \multirow[t]{2}{*}{ Sea water DMS concentration } & $2 \mathrm{nmoll}^{-1}$ & 1 & 105 & -17 \\
\hline & & 4 & 152 & +21 \\
\hline \multirow[t]{2}{*}{ Wind speed at $10 \mathrm{~m}$ height } & $8 \mathrm{~ms}^{-1}$ & 4 & 76 & -40 \\
\hline & & 12 & 194 & +54 \\
\hline \multirow[t]{2}{*}{ MBL height } & $1000 \mathrm{~m}$ & 500 & 126 & 0 \\
\hline & & 1500 & 120 & -5 \\
\hline \multirow[t]{2}{*}{ Entrainment velocity } & $0.36 \mathrm{~cm} \mathrm{~s}^{-1}$ & 0.18 & 122 & -3 \\
\hline & & 0.54 & 123 & -2 \\
\hline \multirow[t]{2}{*}{ Relative Humidity } & 0.8 & 0.7 & 119 & -6 \\
\hline & & 0.9 & 141 & +12 \\
\hline Precipitation frequency & $1 / 10$ days & $1 / 5$ & 113 & -10 \\
\hline \multirow[t]{2}{*}{ Cloud frequency } & $1.0 \mathrm{day}^{-1}$ & 0.5 & 137 & +9 \\
\hline & & 1.5 & 120 & -5 \\
\hline \multirow[t]{2}{*}{$(\mathrm{OH}) \mathrm{g}$ max value } & $5 \times 10^{6}$ molecule $\mathrm{cm}^{-3}$ & $2.5 \times 10^{6}$ & 104 & -17 \\
\hline & & $7.5 \times 10^{6}$ & 142 & +13 \\
\hline \multirow[t]{2}{*}{$\mathrm{SO}_{2}$ yield rate from DMS oxidation } & 0.9 & 0.7 & 118 & -6 \\
\hline & & 1.0 & 130 & +3 \\
\hline \multirow{2}{*}{$\mathrm{SO}_{2}$ deposition velocity } & $0.5 \mathrm{~cm} \mathrm{~s}^{-1}$ & 0.25 & 130 & +3 \\
\hline & & 1.00 & 121 & -4 \\
\hline \multirow{2}{*}{$\mathrm{H}_{2} \mathrm{SO}_{4}$ deposition velocity } & $1.0 \mathrm{~cm} \mathrm{~s}^{-1}$ & 0.5 & 126 & 0 \\
\hline & & 1.5 & 126 & 0 \\
\hline \multirow[t]{2}{*}{ Accommodation coefficient } & 0.70 & 0.35 & 120 & -5 \\
\hline & & 0.90 & 129 & +2 \\
\hline$D_{1}$ & $0.023 \mu \mathrm{m}$ & 0.001 & 77 & -39 \\
\hline$D a$ & $0.1 \mu \mathrm{m}$ & 0.05 & 190 & +51 \\
\hline$D_{2}$ & $0.6 \mu \mathrm{m}$ & 1.0 & 116 & -8 \\
\hline \multirow[t]{2}{*}{ Aitken nuclei deposition velocity } & $0.04 \mathrm{~cm} \mathrm{~s}^{-1}$ & 0.02 & 127 & +1 \\
\hline & & 0.08 & 125 & -1 \\
\hline \multirow[t]{2}{*}{ CCN deposition velocity } & $0.06 \mathrm{~cm} \mathrm{~s}^{-1}$ & 0.03 & 131 & +4 \\
\hline & & 0.12 & 118 & -6 \\
\hline \multirow{2}{*}{ Nucleation empirical coefficient } & 10 & 5 & 126 & 0 \\
\hline & & 15 & 139 & +10 \\
\hline
\end{tabular}

case when FT air was free of aerosols but the entrainment existed. In this case, MBL CCN concentration was predicted as only $39 \mathrm{~cm}^{-3}$. About half of this concentration were derived from SS CCN $\left(18 \mathrm{~cm}^{-3}\right)$, so the nucleation process alone explained only $21 \mathrm{~cm}^{-3} \mathrm{CCN}$ concentration in this case.

\subsubsection{Sensitivity to each parameters}

The results of sensitivity tests for each parameter that were used in the default case simulation are listed in Table 1. The two most sensitive factors that affected the concentration of MBL CCN were seawater DMS concentration and the mean wind speed, because these provided the direct sources. The relationships between $\mathrm{CCN}$ and these two factors are discussed in detail in Sect. 3.3.
For the base case simulation, a value of 10 was used for an empirical enhancement factor to reflect not only binary nucleation, but also ternary nucleation effects. It was found that a variation in this coefficient could not affect the modelled MBL CCN concentration seriously. This was because the concentration of sulfuric acid was very small due to transfer processes and the nucleation alone cannot be the main source of MBL CCN.

The choice of a reliable $\mathrm{CCN}$ activation diameter was found to be very important. When $0.05 \mu \mathrm{m}$ for this parameter, modelled potential $\mathrm{CCN}$ concentration was increased by $51 \%$, but this meant that the concentration of Aitken mode aerosols was decreased by this factor. The activation diameter of $\mathrm{CCN}$ is, in practice, dependent on the supersaturation, so the lower activation diameter limit means more $\mathrm{CCN}$ 

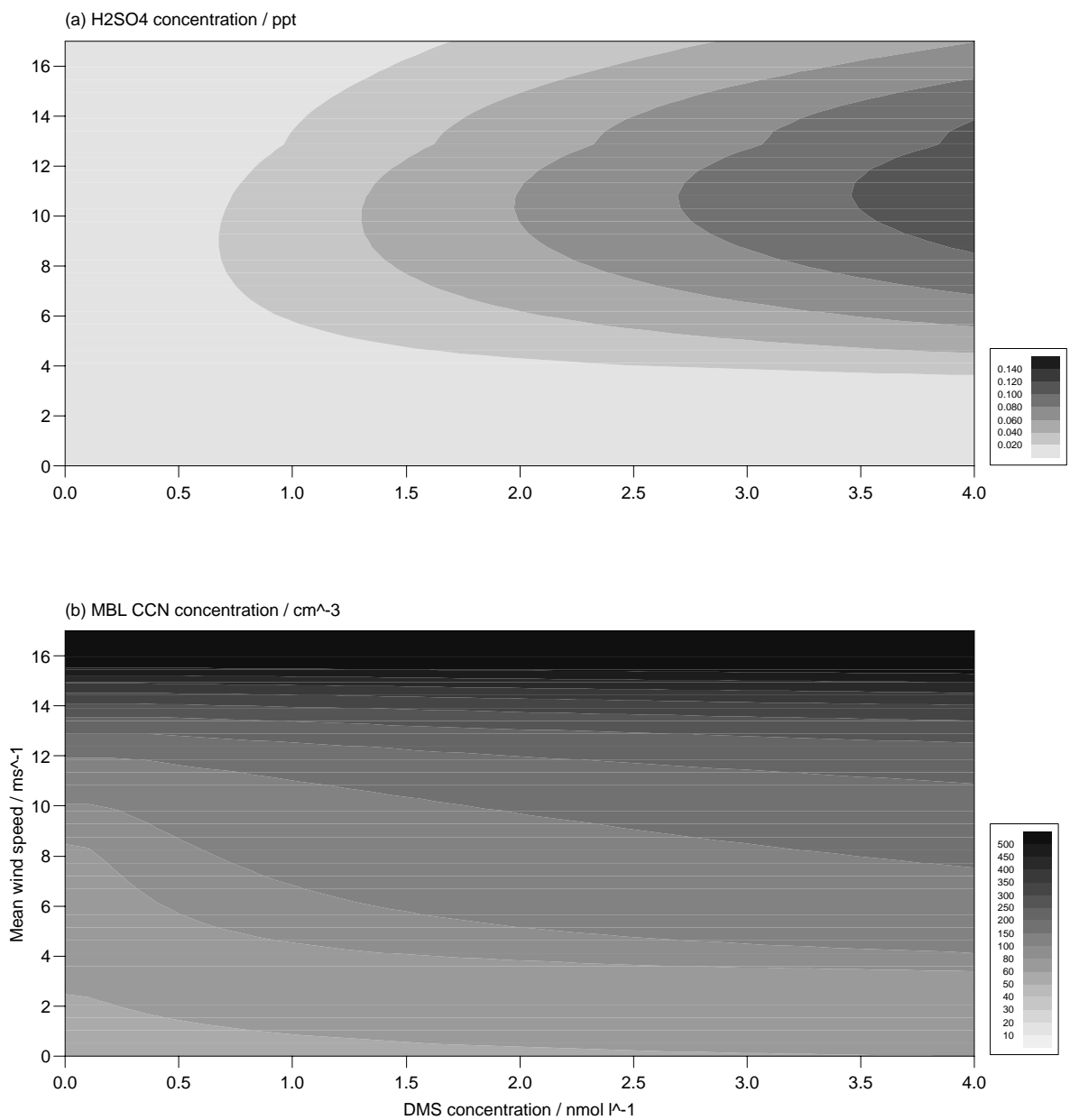

Fig. 7. Predicted distributions of (a) gaseous $\mathrm{H}_{2} \mathrm{SO}_{4}(\mathrm{ppt})$, and (b) $\mathrm{MBL} \mathrm{CCN}\left(\mathrm{cm}^{-3}\right)$ concentration. This simulation used the default parameters except for seawater DMS concentration and mean wind speeds.

available in the MBL with a lower supersaturation. This effect was not included in the modelling work reported here.

\subsection{MBL CCN concentration for various seawater DMS concentrations and wind speeds}

The estimation of MBL CCN for various wind speeds and seawater DMS concentrations was performed to show more complete picture of these relationships. These results for base case simulations are shown in Figs. 7 and 8. Figure 7a and $b$ show the default case concentrations for predicted sulfuric acid and MBL CCN, respectively. In the case of the sulfuric acid, the concentration distribution was non- linear with respect to DMS concentration and wind speed. At low seawater DMS concentration, the concentration of sulfuric acid was very low because the DMS flux was also very weak. When seawater was highly concentrated with DMS, the flux affected the sulfuric acid amount more strongly, via wind speeds and transfer processes. The maximum sulfuric acid concentration occurred when the DMS concentra- tion was high (around $4 \mathrm{nmol} \mathrm{l}^{-1}$ ) and mean wind speed was between 10 and $12 \mathrm{~m} \mathrm{~s}^{-1}$. Predicted MBL CCN is shown in Fig. 7b. This pattern differed from that of sulfuric acid because of the SS contribution. The MBL CCN concentration was more sensitive to mean wind speed than the seawater DMS concentration. For example, at a wind speed of $8 \mathrm{~m} \mathrm{~s}^{-1}$, CCN concentration was not very variable as DMS concentration changed, but at DMS concentrations of $2 \mathrm{nmol}$ $1^{-1}$, the CCN concentration increased sharply as wind speed increased. In case of constant seawater DMS concentration, wind speed affected the $\mathrm{CCN}$ formation system by affecting both the DMS flux and the SS CCN production. As a result, at extreme high wind speeds, $\mathrm{CCN}$ concentration was not affected by DMS concentration. The DMS concentration variation affected $\mathrm{CCN}$ concentration only when the mean wind speed was weak.

This NSS CCN distribution was plotted (Fig. 8). to examine the CCN derived from NSS sources alone. The SS $\mathrm{CCN}$ contribution to the MBL CCN was omitted in this simulation so this figure represented the DMS CCN and the FT 


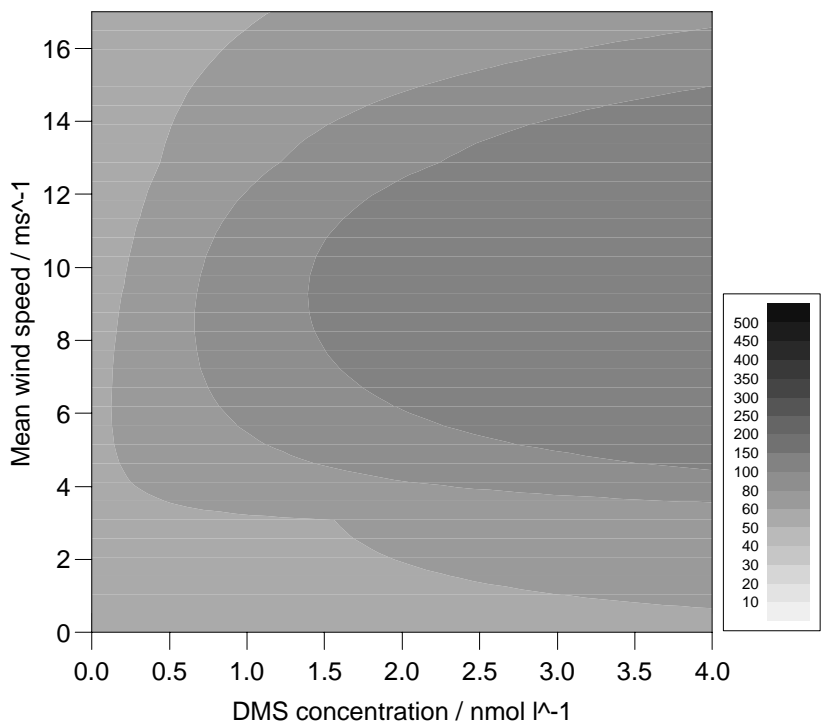

Fig. 8. Predicted $\mathrm{CCN}$ concentration $\left(\mathrm{cm}^{-3}\right)$ when these are assumed to be composed of NSS CCN only. The flux of SS CCN was omitted in this simulation.

CCN distribution only. This pattern was similar to the sulfuric acid distribution because of their nucleation processes. The concentration of the NSS CCN increased as wind became stronger, but at high wind speeds, it decreased again. This arose from the lack of sulfuric acid under these conditions, where the transfer processes of sulfuric acid onto aerosol were very active. The maximum NSS CCN concentration did not exceed $150 \mathrm{~cm}^{-3}$, and occurred at high DMS concentrations and moderate wind speed.

This NSS CCN accounted for less than $10 \%$ of the total predicted $\mathrm{CCN}$ at high wind speed regardless of DMS concentration. Nevertheless the NSS CCN played a major component in marine $\mathrm{CCN}$ system when wind speed was less than $6 \mathrm{~m} \mathrm{~s}^{-1}$. For these wind speeds, the NSS CCN accounted for more than $70 \%$ of the predicted total MBL CCN. The SS CCN accounted for more than $80 \%$ of the total predicted CCN when wind speed exceeded $12 \mathrm{~m} \mathrm{~s}^{-1}$.

\subsection{Comparison with other results}

The MBL CCN model results were compared with the observed CCN concentration at Cape Grim $\left(40^{\circ} \mathrm{S}, 144^{\circ} \mathrm{E}\right)$. Monthly CCN data at Cape Grim (Ayers et al., 1997; Ayers and Gras, 1991; Gras, 1989, 1990) were collected and the MBL CCN for the location were estimated for each month. For this comparison, monthly DMS concentration was extracted from Kettle et al. (1999)'s global data and monthly mean wind speeds were adopted from da Silva et al, (1994). Other parameters are the same as the base case simulation.

The observed and modelled $\mathrm{CCN}$ concentrations are shown in Fig. 9. The climatological wind data (da Silva et al., 1994) showed that the annual fluctuation for the loca-

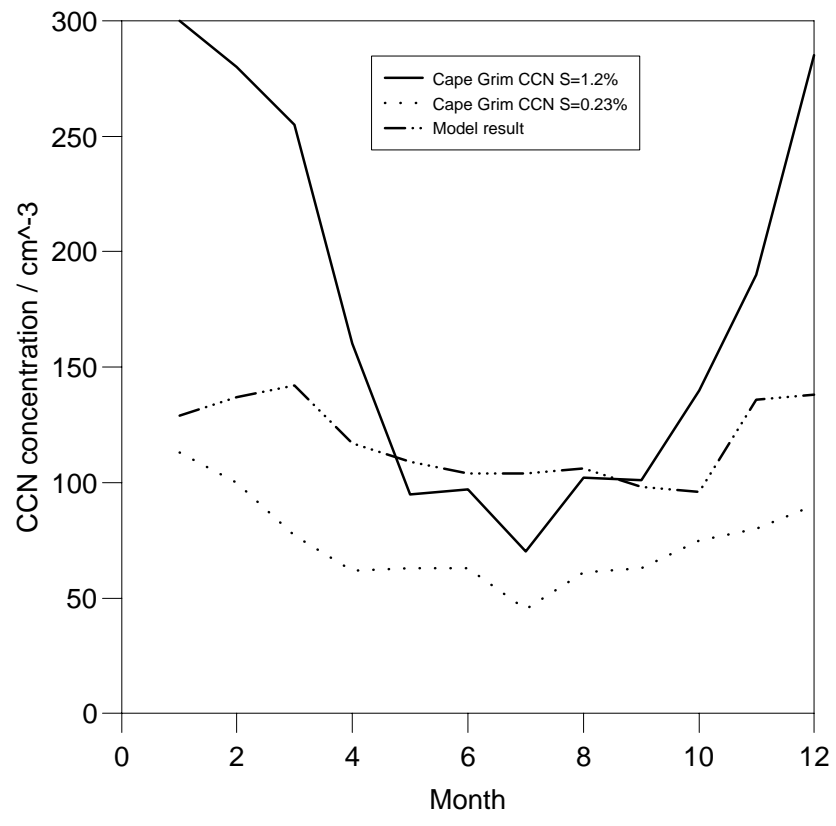

Fig. 9. Comparison of modelled results with Cape Grim CCN data. The dashed line is from the simulation. The solid and dotted line represent the CCN concentration for Cape Grim at 1.2 and $0.23 \%$ supersaturation, respectively.

tion was smaller than DMS concentration variation (Kettle et al., 1999). The weakest monthly wind speed was $8 \mathrm{~m} \mathrm{~s}^{-1}$ in February, and the maximum was $9 \mathrm{~m} \mathrm{~s}^{-1}$ in August. The predicted SS CCN concentration varied from 16 to $31 \mathrm{~cm}^{-3}$. In contrast, the concentration of seawater DMS showed a minimum $\left(0.5 \mathrm{nmol}^{-1}\right)$ in October and a maximum $(3.1 \mathrm{nmol}$ $1^{-1}$ ) in March. Because the monthly mean wind speed was less variable than the seawater DMS concentration, the estimated MBL CCN were mainly affected by the variation of seawater DMS, shown as a dashed line in Fig. 9. The predicted MBL CCN showed a maximum in austral summer and minimum in winter, respectively. The maximum MBL CCN concentration was simulated as $142 \mathrm{~cm}^{-3}$ in March, and the minimum was $96 \mathrm{~cm}^{-3}$ in October. This seasonal change was predicted to be similar to the observed $\mathrm{CCN}$, but the predicted CCN for the austral winter season was about $10 \%$ higher than the observed value. This is mainly because of the $\mathrm{OH}$ radical concentration. In this simulation, $\mathrm{OH}$ maximum value was assumed to be same all the year round, and this simplified assumption may over predict the DMS oxidation in the winter and underestimate for the summer. The activation diameter of $\mathrm{CCN}$ is dependent on the supersaturation, and the lower supersaturation means larger activation diameter limit and this leads less CCN available in the MBL as shown in Cape Grim data. This effect was not included in the work reported here. Nevertheless, the modelled MBL CCN concentration lay between $1.20 \%$ and $0.23 \%$ supersaturation $\mathrm{CCN}$ data (solid and dotted lines) for the other seasons. 
The model was run with DMS flux as a variable. This DMS flux was also dependent on DMS concentration and wind speeds so this aim was to compare the results with other empirical and model relations between DMS flux and CCN concentration. Figure 10 shows the simulated results for various wind speeds, such as $2,4,8,12$, and $16 \mathrm{~m} \mathrm{~s}^{-1}$. For moderate and weak wind speeds, predicted MBL CCN lay between 150 and $200 \mathrm{~cm}^{-3}$ as the DMS flux changed. For the high mean wind speeds, for example at $16 \mathrm{~m} \mathrm{~s}^{-1}$, MBL CCN concentration was $590 \mathrm{~cm}^{-3}$ and showed almost no slope with DMS flux increases because SS CCN was the major component above this extremely high wind speed. These estimations are compared with the empirical relationship of Lawrence (1993) and model results of Pandis et al. (1994), in Fig. 10.

The present MBL CCN model results are in accord with these two relationships for various wind speeds as shown in Fig. 10. Even for a high mean wind speed, such as $14 \mathrm{~m} \mathrm{~s}^{-1}$, the modelled MBL CCN agreed well with the relationship of Lawrence (1993). For this wind speed, DMS flux less than $5 \mu \mathrm{mol} \mathrm{m}^{-2} \mathrm{~d}^{-1}$ is very rare unless the seawater DMS concentration is very small. When compared with the steady state model results of Pandis et al. (1994), the simulated CCN concentration was larger for the weak DMS flux regime, and smaller for the strong DMS flux. These results suggests that the role of DMS flux in formation of MBL CCN is weaker than offered by Pandis et al. (1994)'s because of the SS contributions, sulfuric acid transfer onto aerosols, and FT entrainment processes.

\subsection{Discussions}

The P\&R model, which we adapted and modified for this study, is composed of only two aerosol size bins, and this simplified approach has been discussed in detail between Reas and Van Dingenen (1995) and Pandis et al. (1995). Because of the simplified aerosol size distribution, some dynamical information might have not been included in this study. This approach might not be able to fully reflect the nucleation of new particles and their growth from $0.001 \mu \mathrm{m}$ to the first bin $(0.023-0.1 \mu \mathrm{m})$, though we tried to tune the nucleation rate by adopting an empirical enhancement factor $10^{10}$ - see reaction (4) in Pandis et al. (1994) - from Katoshevski et al. (1999). As already been discussed by Katoshevski et al. (1999) and Pirjola et al. (2000), theoretical binary nucleation rate have failed to reproduce the MBL aerosol. Pirjola et al. (2000) also elucidated the even ternary nucleation can hardly contribute to the general MBL aerosol concentration exept for the case when there is a significant removal of MBL aerosol such as due to precipitation. It is likely that whether a classical nucleation or tuned rate is used, this does not effect the MBL CCN vatiation seriously when compared with the effects due to mean wind speed. For example, a sensitivity test of this empirical factor showed $10 \%$ increase in $\mathrm{CCN}$ concentration with the value $10^{5}$, re-

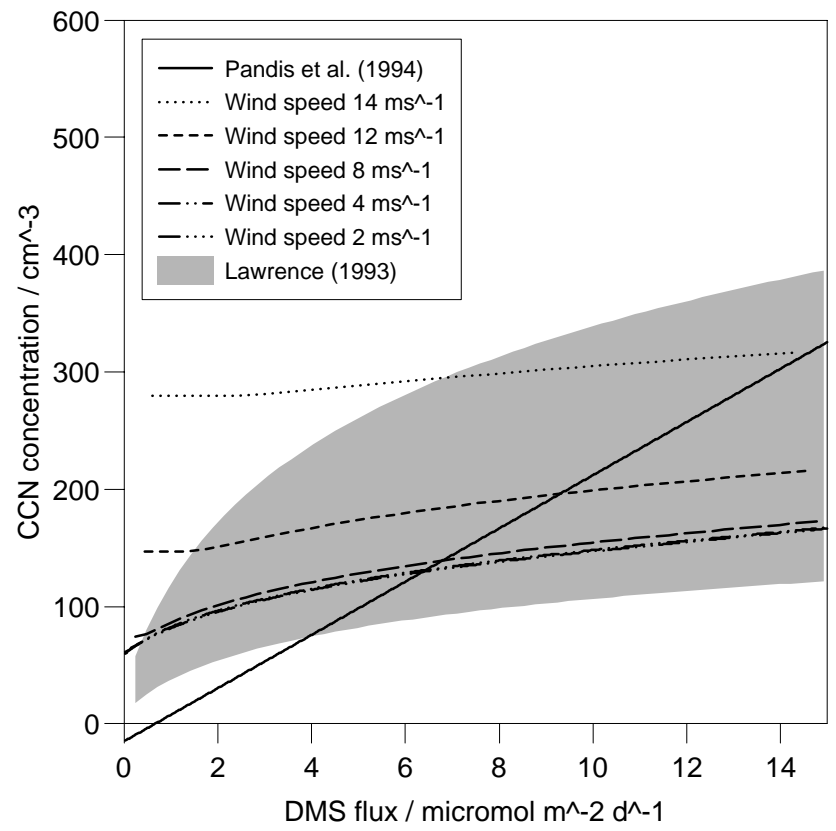

Fig. 10. Modelled MBL CCN concentration as a function of DMS flux changes and other empirical suggestions. The solid line is the result of Pandis et al. (1994), and the shaded area represents the empirical relationship suggested by Lawrence (1993).

spectively. By contrast, changes in wind speed from $8 \mathrm{~m} \mathrm{~s}^{-1}$ to $4 \mathrm{~m}^{-1}$ and from $8 \mathrm{~m} \mathrm{~s}^{-1}$ to $12 \mathrm{~m}^{-1}$ showed CCN concentrations to decrease by $40 \%$ and increase by $54 \%$, respectively. It is obvious that the contribution of DMS to MBL $\mathrm{CCN}$ is suppressed by wind speed because of direct contribution of sea salt to CCN concentration. Latham and Smith (1991) have already suggested a negative feedback process between global warming and increased wind generated sea salt particles. Even though physico-chemical processes of the recently formed ultra-fine particles and growth of Aitken mode particles into $\mathrm{CCN}$ were simplified in our approach due to the limited aerosol size distribution, this important role of sea salt CCN should b seriously projected into the hypothesis between climate change and feedback due to marine biological activity and sea salt concentration change.

The result here not only highlights a direct sea salt contribution to $\mathrm{CCN}$ concentration, but also elucidates an additional role for sea salt particles in suppressing the action of DMS in global climate change scenatios - the mass transfer process of sulfuric acid onto wind generated SS CCN. As discussed in Sect. 3.3, NSS CCN concentration showed nonlinear dependency on wind speed and seawater DMS concentration. The role of DMS in CCN formation seems seriously decreased when wind speeds are moderate and high. This means that sea salt CCN act as an efficient sink of DMS derived sulfuric acid. The DMS derived $\mathrm{SO}_{2}$ also efficiently react in sea salt cloud droplets (O'Dowd et al. , 1997), then reduce the production rate of NSS CCN. Though DMS flux 
as a function of wind speed was not dealt with in O'Dowd et al. (1999b) as in our approach, they also postulated a reduced role of DMS in cloud droplet formation. Even more, condensation of sulfuric acid onto super micron jet drop sea salt particles, which was not considered in this study, is nearly three times greater than that onto accumulation mode distribution according to a calculation by O'Dowd et al. (1997). This means that even our study might have overestimated the role of DMS in CCN formation in MBL due to the lack of sulfuric acid condensation onto super-micron sea salt particles. This fact also supports the importance of selection of accommodation coefficient when modeling the $\mathrm{CCN}$ concentration in marine environment as suggested by Pandis et al. (1995).

\section{Conclusions}

For completeness, the model and the concept used in this study should further include other sources of marine $\mathrm{CCN}$, such as anthropogenic contributions from shipping (Capaldo et al. , 1999; Huebert, 1999), volcanic emission (Graf et al., 1997), and transport of aerosols from continents. In case of considering other $\mathrm{CCN}$ sources to the marine atmosphere, a more complicated chemical-transport scheme should be added. In addition, nucleation processes in the MBL, and the relation between SS CCN and the wind speed should be further investigated. Each of these factors could yield an uncertainty with a factor of at least two.

Though many uncertainties remain in this study, some important findings and hypotheses result from this work. The sea salt flux from the sea surface is an important factor in the MBL CCN formation. The SS CCN can directly affect the system by providing more than $70 \%$ of total $\mathrm{CCN}$ observed in the MBL, especially for winter seasons over middle and high latitude regions. The modelling study in this work also suggests the possibility of an indirect SS aerosol effect. This indirect effect provides a sink for gaseous sulfuric acid through mass transfer suppressing the efficiency of nucleation of sulfuric acid in the MBL.

Sulfuric acid nucleation in the MBL is highly dependent on the mass transfer process onto existing aerosols. As a result, selection of an appropriate accommodation coefficient is a key issue in modelling the relationship between the DMS flux and the MBL CCN concentration. A selection of lower accommodation coefficients tends to yield the result that the amount of MBL CCN is highly dependent on the DMS flux. By contrast, this paper, which used 0.7 as the accommodation coefficient, showed that the relationship between MBL CCN concentration and DMS flux (or seawater DMS concentration) is not linear. This non-linearity arose from the direct CCN sources, such as SS and entrained accumulation mode aerosol, and the active transfer of sulfuric acid onto aerosols. In general, the FT aerosols and SS CCN similarly contribute to the MBL CCN concentration. The two direct source of CCN, SS and FT aerosol may be more important than the aerosol formed from the oxidation of MBL (DMS)g.

The key parameter which affects MBL CCN concentration and, in turn, the indirect radiative effect, may be wind speed, on which the SS emission rate and the DMS flux are highly dependent. A change in the global wind speed could influence the MBL CCN system and ultimately global radiation budget. This process could be more efficient than the CLAW hypothesis which focused on the relationship between temperature and DMS flux changes.

\section{References}

Andreae, M. O., Elbert, W., and de Mora, S. J.: Biogenic sulphur emissions and aerosols over the tropical South Atlantic. 3. Atmospheric dimethylsulfide, aerosols and cloud condensation nuclei, J. Geophys. Res., 100, 11 335-11 356, 1995.

Ayers, G. P. and Gras, J. L.: Seasonal relationship between cloud concentration nuclei and aerosol methanesulphonate in marine air, Nature, 353, 834-835, 1991.

Ayers, G. P., Cainey, J. M., Gillett, R. W., and Ivey, J. P.: Atmospheric sulphur and cloud condensation nuclei in marine air in the Southern Hemisphere, Philos. T. Roy. Soc., B 352, 203-211. 1997.

Blanchard, D. C. and Cipriano, R. J.: Biological regulation of climate, Nature, 330, 526, 1987.

Capaldo, K., Corbett, J. J., Kasibhatla, P., Fischbeck, P., and Pandis, S.: Effects of ship emissions on sulphur cycling and radiative climate forcing over ocean, Nature, 400, 743-746, 1999.

Charlson, R. J., Lovelock, J. E., Andreae, M. O., and Warren, S. G.: Oceanic phytoplankton, atmospheric sulphur, cloud albedo and climate change, Nature, 326, 655-661, 1987.

Cipriano, R. J., Monahan, E. C., Bowyer, P. A., and Woolf, D. K.: Marine condensation nucleus generation inferred from whitecap simulation tank results, J. Geophys.Res., 92, 6569-6576, 1987.

Clarke, A. D.: Atmospheric nuclei in the remote free-troposphere, J. Atmos. Chem., 14, 479-488, 1992.

Clarke, A. D., Davis, D., Kapustin, V. N., Eisele, F., Chen, G., Paluch, I., Lenschow, D., Bandy, A. R., Thornton, D., Moore, K., Mauldin, L., Tanner, D., Litchy, M., Carroll, M. A., Collins, J., and Albercook, G.: Particle nucleation in the tropical boundary layer and its coupling to marine sulfur sources, Science, 282, 89-92, 1998a.

Clarke, A. D., Varner, J. L., Eisele, F., Mauldin, R. L., Tanner, D., and Litchy, M.: Particle production in the remote marine atmosphere: Cloud outflow and subsidence during ACE1, J. Geophys. Res., 103, 16397-16409, 1998 b.

Clarke, A. D., Eisele, F., Kapustin, V. N, Moore, K., Tanner, D., Mauldin, L., Litchy, M., Lienert, B., Carroll, M. A., and Albercook, G.: Nucleation in the equatorial free troposphere: Favorable environments during PEM-Tropics, J Geophy. Res., 104, 5735-5744, 1999.

Da Silva, A., Young, A. C., and Levitus, S.: Atlas of surface marine data 1994, Volume 1; Algorithms and procedures., NOAA Atlas NESDIS 6, U. S. Department of Commerce, Washington D. C., 1994. 
Erickson, D. J., III and Taylor, J. A.: Non-Weibull behavior observed in a model-generated global surface wind field frequency distribution, J. Geophys. Res., 94, 12 693-12 699, 1989.

Fitzgerald, J. W. and Hoppel, W. A.: A one-dimensional sectional model to simulate multicomponent aerosol dynamics in the marine boundary layer, J. Geophys. Res., 103, 16 085-16 102, 1998.

Graf, H.-F., Feichter, J., and Langmann, B.: Volcanic sulfur emissions: Estimates of source strength and its contribution to the global sulfate distribution, J. Geophys. Res., 102, 10727-10 738, 1997.

Gras, J. L.: Baseline atmospheric condensation nuclei at Cape Grim, J. Atmos. Chem., 11, 89-106, 1989.

Gras, J. L., Cloud condensation nuclei over the Southern Ocean, Geophys. Res. Lett., 17, 1565-1567, 1990.

Hobbs, P. V.: Simultaneous airborne measurements of cloud condensation nuclei and sodium-containing particles over the ocean, Q. J. Roy. Meteor. Soc., 97, 263-271, 1971.

Huebert, B. J., Wylie, D. J., Zhuamg, L., and Heath, J. A.: Production and loss of methanesulfonate and non-sea salt sulfate in the equatorial Pacific marine boundary layer, Geophys. Res. Lett., 23, 737-470, 1996.

Huebert, B.: Sulphur emissions from ships, Nature, 400, 713-714, 1999.

Jefferson, A., Eisele, F. L., Ziemann, P. J., Weber, R. J., Marti, J. J., and McMurry, P. H.: Measurements of $\mathrm{H}_{2} \mathrm{SO}_{4}$ mass accommodation coefficient onto polydisperse aerosol., J. Geophys. Res., 102, 19021-19028, 1997.

Johnson, D. W., Osborne, S., Wood, R., Suhre, K., Quinn, P. A., Bates, T., Andreae, M. O., Noone, K. J., Glantz, P., Bandy, B., Rudolph, J. and O'Dowd, C.: Observations of the evolution of the aerosol, cloud and boundary-layer characteristics during the 1st ACE-2 Lagrangian experiment, Tellus, 52B, 348-374, 2000.

Kettle, A. J., Andreae, M. O., Amouroux, D., Andreae, T. W., Bates, T. S., Berresheim, H., Bingemer, H., Boniforti, R., Curran, M. A. J., Di Tullio, G. R., Helas, G., Jones, G. B., Keller, M. Kiene, R. P., Leck, C., Levasseur, M., Malin, G., Maspero, M., Matrai, P., McTaggart, A. R., Mihalopoulos, N., Nguyen, B. C., Novo, A., Putaud, J. P., Rapsomanikis, S., Roberts, G., Schebeske, G., Sharma, S., Simo, R., Staubes, R., Turner, S., and Uher, G.: A global database of sea surface dimethylsulfide (DMS) measurements and a procedure to predict sea surface DMS as a function of latitude, longitude, and month, Global. Biogeochem. Cy., 13, 399-444, 1999.

Katoshevski, D., Nenes, A., Seinfeld, J. H.: A study of processes that govern the maintenance of aerosols in the marine boundary layer, J. Aerosol Sci., 30, 503-532, 1999.

Kritz, M. A.: Use of long-lived radon daughters as indicators of exchange between the free troposphere and the marine boundary layer, J. Geophys. Res., 88, 8569-8573, 1983.

Lantham, J. and Smith, M. H.: Effect on global warming of winddependent aerosol generation at the ocean surface, Nature, 347, 372-373, 1990.

Lawrence, M. G.: An empirical analysis of the strength of the phytoplankton-dimethylsulfide-cloud-climate feedback cycle, J. Geophys. Res., 98, 20 663-20 673, 1993.

Murphy, D. M., Anderson, J. R., Quinn, P. K., Mclnnes, L. M., Brechtel F. J., Kreidenweis, S. M., Middlebrook, A. M., Posfai, M., Thomson, D. S., and Buseck, P. R.: Influence of sea-salt on aerosol radiative properties in the southern Ocean marine bound- ary layer, Nature, 392, 62-65, 1998.

O'Dowd, C. D. and Smith, M. H.: Physicochemical Properties of Aerosols over the Northeast Atlantic: Evidence for wind-speedrelated submicron sea-salt aerosol production, J. Geophys. Res., 98, 1137-1149, 1993.

O’Dowd, C. D., Smith, M. H., Consterdine, I. E., and Lowe, J. A.: Marine aerosol, sea-salt, and the marine sulphur cycle: A short review, Atmos. Environ., 31, 73-80, 1997.

O’Dowd, C. D., Lowe, J. A., Smith, M. H., and Kaye, A. D.: The relative importance of non-sea-salt sulphate and sea-salt aerosol to the marine cloud condensation nuclei population: An improved multi-component aerosol-cloud droplet parameterization, Q. J. Roy. Meteor. Soc., 125, 1295-1313, 1999.

O’Dowd, C. D., Lowe, J. A., and Smith, M. H.: Cloupling sea-salt and sulphate interactions and its impact on cloud droplets concentration predictions, Geophy. Res. lett., 26, 1311-1314, 1999b.

Pandis, S. N., Russel, L. M., and Seinfeld, J. H.: The relationship between DMS flux and CCN concentration in remote marine regions, J. Geophys. Res., 99, 16945-16957, 1994.

Pandis, S. N., Russel, L. M., and Seinfeld, J. H.: Reply to Comment on "The relationship between DMS flux and CCN concentration in remote marine regions", J. Geophys. Res. 100, 14 357-14358, 1995.

Pirjola, L., O'Dowd, C. D., Brooks, I. M., and Kulmala, M.: Can new particle formation occur in the clean marine boundary layer? J. Geophys. Res., 105, 26 531-26 546, 2000.

Raes, F. and Van Dingenen, R.: Comment on "The relationship between DMS flux and CCN concentration in remote marine regions", J. Geophys. Res. 100, 14355-14 356, 1995

Raes, F.: Entrainment of free tropospheric aerosols as regulating mechanism for cloud condensation nuclei in the remote marine boundary layer, J. Geophys. Res., 100, 2893-2903, 1995.

Raes, F., Bates, T., McGovern, F., and Van Liedekerke, M.: The 2nd Aerosol Characterization Experiment (ACE-2): general overview and main results, Tellus, 52B, 111-125, 2000.

Russell, L. M., Pandis, S. N., and Seinfeld, J. H.: Aerosol production and growth in the boundary layer, J. Geophys. Res., 99, 20 989-21 003, 1994.

Sollazzo, M. J., Russell, L. M., Percival, D., Osborne, S., Wood, R., and Johnson, D. W.: Entrainment rates during ACE-2 Lagrangian experiments calculated from aircraft measurements, Tellus, 52B, 335-347, 2000.

Turner, S. M., Malin, G., Nightingale, P. D., and Liss, P.: Seasonal variation of dimethylsulphide in the North sea and an assessment of fluxes to the atmosphere, Mar. Chem., 54, 245-262, 1996.

Van Dingenen, R. and Raes, F.: Determination of the condensation accommodation coefficient of sulfuric acid on water-sulfuric acid aerosol, Aerosol Sci. Technol., 15, 93-106, 1991.

Wanninkhof, R.: Relation between wind speed and gas exchange over ocean, J. Geophys. Res., 97, 7373-7382, 1992.

Weber, R. J. and Mcmurry, P. H.: Fine particle size distributions at the Mauna Loa Observatory, Hawaii, J. Geophys. Res., 101, 14767-14 775, 1996.

Weber, R. J., Marti, J. J., McMurry, P. H., Eisele, F. L., Tanner, D. J., and Jefferson, A.: Measurements of new particle formation and ultrafine particle growth rates at a clean continental site, J. Geophys. Res., 102, 4375-4385, 1997.

Weber, R. J., Mcmurry, P. H., Mauldin, L., Tanner, D. J., Eisele, F. L., Brechtel, F. J., Kreidenweis, S. M., Kok, G. L., Schillawski, 
R. D., and Baumgardner, D.: A study of new particle formation and growth involving biogenic and trace gas species measured during ACE 1, Geophys. Res., 103, 16385-16396, 1998.

Yvon, S. A. and Saltzman, E. S.: Atmospheric sulfur cycling in the tropical Pacific marine boundary layer $\left(12^{\circ} \mathrm{S}, 135^{\circ} \mathrm{W}\right)$ : A comparison of field data and model results 2 . Sulfur dioxide, J. Geo- phys. Res., 101, 6911-6918, 1996.

Yvon, S. A., Saltzman, E. S., Cooper, D. J., Bates, T. S., and Thompson, A .M.: Atmospheric sulfur cycling in the tropical Pacific marine boundary layer $\left(12^{\circ} \mathrm{S}, 135^{\circ} \mathrm{W}\right)$ : A comparison of field data and model results 1 . Dimethylsulfide, J. Geophys. Res., 101, 6899-6909, 1996. 